\section{Acknowledgment}

We wish to thank the Department of Chemical Pathology for their collaboration, and Dr Percy Cliffe for making the photomotogram. Part of the costs of this study were met by a grant from the Research Fund of the Westminster Hospital Board of Governors.

\section{References}

Abraham, A.S., Atrinson, M. \& Roscoe, B. (1966) Value of ankle-jerk timing in the assessment of thyroid function. Brit. med. J. i, 830.

Avera, J.W. \& Overholt, B.M. (1962) Achilles tendon reflex relaxation time. Amer. Practit. 13, 251.

BAYLISS, R.I.S. (1967a) Stimulation and suppression tests of thyroid function. Proc. roy. Soc. Med. 60, 303.

BAYLISS, R.I.S. (1967b) Stimulation and suppression tests of thyroid function. J. clin. Path. 20, 360.

Beardwood, D.M. \& Schumacher, L.R. (1964) Delay of the Achilles reflex in diabetes mellitus. Amer. J. med. Sci. 247, 324.

Carr, A.A., Gill, J.R., JR, Henkin, R.I. \& BartTer, F.C. (1963) The relationship of potassium metabolism to the Achilles tendon reflex in man. Clin. Res. 11, 215.

Chaney, W.C. (1924) Tendon reflexes in myxoedema: a valuable aid in diagnosis. J. Amer. med. Ass. 82, 2013.

FeJer, A.Gy. \& Kun, M. (1963) The Achilles reflex. (Letter). Lancet, ii, 695.

Fogel, R.L., Epstein, J.A., StopaK, J.H. \& Kupperman, H.S. (1962) Achilles tendon reflex (photomotogram) as a measure of thyroid function. N.Y. St. J. Med. 62, 1159.

Fournier, J.C.M. (1929) Trastornos del Sistema Nervioso de Origen Mixedematoso, p. 29. Barreiro y Ramos S.A., Montevideo.

Galpin, O.P. \& O'Brien, P.K. (1964) Prolongation of tendon reflexes in ischaemia. (Letter). Lancet, ii, 209.

GiLson, W.E. (1959) Achilles reflex recording with a simple photomotograph. New Engl. J. Med. 260, 1027.

GoldberG, M. (1962) Comparative study of the adrenergic potentiating properties of various thyroid analogs in man. J. clin. Endocr. 22, 892.

Harrell, G.T. \& Daniel, D. (1941) Delayed relaxation of tendon reflexes as an aid in the diagnosis of myxoedema. N.C. med. J. 2, 549.

Hobbs, J.R., Bayliss, R.I.S. \& Maclagan, N.F. (1963) The routine use of ${ }^{132} \mathrm{I}$ in the diagnosis of thyroid disease. Lancet, i, 8.
LAMBerT, E.H., UNDERDAHL, L.D., BecketT, S. \& MEderos, L.O. (1951) A study of the ankle jerk in myxoedema.J. clin. Endocr. 11, 1186.

LAwSON, J.D. (1958) The free Achilles reflex in hypothyroidism and hyperthyroidism. New Engl. J. Med. 259, 761.

MaNN, A.S. (1963) The value of kinemography in the diagnosis of thyroid dysfunction. Amer. J. med. Sci. 245, 317.

Miles, D.W. \& SuRveyor, I. (1965) Role of the ankle-jerk in the diagnosis and management of thyroid disease. Brit. med. J. i, 158 .

Moulopoulos, S.D., Koutras, D.A. \& Kralios, A.C. (1964) A simple inexpensive method for recording Achilles tendon reflexes. Lancet, $\mathrm{i}, 85$.

Nutall, F.Q. \& Doe, R.P. (1964) The Achilles reflex in thyroid disorders. Ann. intern. Med. 61, 269.

ORD, W.M. (1884) On some disorders of nutrition related with affections of the nervous system. Brit. med. J. ii, 205.

Reinfrank, R.F., Kaufman, R.P., Wetstone, H.J. \& GlenNon, J.A. (1967) Observations of the Achilles reflex test. J. Amer. med. Ass. 199, 1.

RichaRds, A.G. (1962) The 'myxoedema reflex' as a presenting sign in sarcoidosis. Canad. med. Ass. J. 86, 32.

Rives, K.L., Furth, E.D. \& BeCKer, D.V. (1965) Limitations of the ankle jerk test: intercomparison with other tests of thyroid function. Ann. intern. Med. 62, 1139.

Robson, A.M., Hall, R. \& SMART, G.A. (1965) A critical evaluation of the tendon reflex measurement as an index of thyroid function. Postgrad. med. J. 41, 518.

Sharpe, A.R. (1961) A simple isotope method for recording the Achilles tendon reflex in myxoedema. J. Lab. clin. Med. 57, 165.

Sherman, L., Goldberg, M. \& Larson, F.C. (1963) The Achilles reflex. A diagnostic test of thyroid dysfunction. Lancet, i, 243.

Simpson, G.M., Blair, J.H. \& Nartowicz, G.R. (1963a) Prolonged Achilles reflex in neurosyphilis simulating the 'myxoedema reflex'. New Engl. J. Med. 268, 89.

Simpson, G.M., Blair, J.H. \& Nartowicz, G.R. (1963b) Diagnostic limitation of Achilles tendon reflex in thyroid: disease. N.Y. St. J. Med. 63, 1148.

Smart, G.A. \& Robson, A.M. (1963) A simple method for recording Achilles tendon reflexes. Lancet, i, 363.

von Binswanger, J., Studer, H. \& Wyss, F. (1961) Der Ablauf der Sehnenreflexebei Funktionsstörungen der Schilddrüse. Helv. med. Acta, 28, 482.

Young, J.A. (1964) The Achilles tendon reflex in thyroid disease. Scot. med. J. 9, 34

\title{
Recent trends in acute viral hepatitis
}

\author{
STUART J. SAUNDERS \\ Department of Medicine, University of Cape Town
}

ACUTE hepatitis is one of the most important infectious diseases to which man is prone. There is good evidence that a virus is the infective agent; but the offending virus or viruses continue to be elusive despite intensive efforts at isolation, both in vivo and in tissue culture (Rightsel, 1967). It is clear that the vital problems are the failure to propagate the infective agent in any host except man, and the consequent absence of any specific diagnostic serological test.

\section{Post-transfusion hepatitis}

While infective hepatitis is usually spread by ingestion, there has been increasing interest in viral hepatitis known to follow injections or similar manoeuvres, and the transfusion of blood, 
serum or blood products. The reported incidence of icteric hepatitis varies from 2.6 to 8.8 cases per thousand units of transfused blood (Hoxworth, Haesler \& Smith, 1959 ; Allen \& Sayman, 1962), while a much larger number of patients are thought to develop anicteric hepatitis after blood transfusion. Hampers, Prager \& Senior (1964) found that $18 \%$ of patients studied prospectively after blood transfusions had evidence of anicteric hepatitis. These patients had anorexia and fatigue, with tenderness of the liver and an increase in the serum glutamic pyruvic and oxaloacetic transaminases. When 175 patients were carefully followed up after blood transfusions in Japan, the incidence of hepatitis was found to be $64.5 \%$ (Shimuzu \& Kitamoto, 1963). In contrast, a prospective study in South Africa has failed to show a high incidence of anicteric hepatitis after blood transfusion. Despite the fact that an epidemic of infective hepatitis was occuring in one of the areas from which donors were being drawn, the incidence of post-transfusion hepatitis was less than 2\% (Albert, Gitlin \& Saunders, 1967, unpublished observations). All donors in South Africa give their blood voluntarily, and it is known that the incidence of hepatitis in patients receiving blood from professional donors is higher than in those receiving blood from volunteers. This is unlikely to account for the difference between the South African and Philadelphia studies, because in the Philadelphia series less than $20 \%$ of the donors were professionals. It is possible that hepatic changes observed by Hampers et al. were not due to the transmission of a virus but were due to some other factor, possibly immunological. The post-transfusional syndrome described by Hampers et al. (1964) is certainly indistinguishable clinically and biochemically from anicteric hepatitis, and it is noteworthy that if this does prove to be due to viral transmission we shall have to revise our concepts of the incubation period, because in the Philadelphia series this varied from 2 to 6 weeks after transfusion, unlike the classic 60-180 weeks usually described.

\section{Anicteric infective hepatitis and cirrhosis}

Only one patient in ten with infective hepatitis develops jaundice (De Ritis et al., 1959). The importance of appreciating the frequency with which viral hepatitis may be anicteric, lies not so much in the better understanding of mild ill-health in the contacts of patients with hepatitis, but rather in the possibility of blood being donated during the viraemia, and also in the consequent development of cirrhosis. One of the major unsolved problems in liver disease is the cause of cirrhosis in non-alcoholic patients. Permanent liver damage rarely complicates hepatitis with jaundice (Zieve et al., 1953 ; Cullinan, King \& Rivers, 1958 ; Nefzger \& Chalmers, 1963) although there is good evidence that it can occur (Shaefer et al., 1967). It is possible that cirrhosis follows on preceding anicteric hepatitis in a significant number of cases. De Ritis et al. (1959) noted a greater correlation between cirrhosis and a history of having lived in a children's institution, where anicteric hepatitis was known to be endemic, than a history of either malnutrition or alcoholism. Further Cooper et al. (1966) found that five of thirty-six cases of anicteric hepatitis progressed morphologically to cirrhosis. In a retrospective study of anicteric hepatitis Klatskin (1958) noted ten cases with progression to post-necrotic cirrhosis. Chung et al. (1964), studying Korean patients with anicteric hepatitis, found that cirrhosis developed within 3 months in $17 \%$. However the true incidence of cirrhosis developing after anicteric hepatitis remains to be established by prospective study of a large number of unselected patients.

Gamma-globulin will diminish the incidence of infectious hepatitis with jaundice, but it probably does not decrease the incidence of anicteric hepatitis (Drake \& Ming, 1954 ; Stokes, 1962). This is probably also true for post-transfusion hepatitis (Mirick, Ward \& McCollum, 1965). It seems likely that the anicteric form after $\gamma$-globulin is a milder disease but, until more is known about the ultimate prognosis of anicteric hepatitis, it is debatable as to whether it is wise give $\gamma$-globulin routinely to contacts. Perhaps at this time the best procedure is to give $\gamma$-globulin to pregnant women, small children or patients with disturbed immunological defence mechanisms, who are close contacts, and to observe these patients for possible anicteric disease.

\section{Viral hepatitis - a generalized disease}

Nineteen of the twenty-five patients with infective hepatitis studied by Conrad, Schwartz \& Young (1964) in Korea developed a mild anaemia. This was associated with a reticulocytosis during the 3rd week of the illness, and a mild haemolytic state was demonstrated during convalescence. Leucopaenia and thrombocytopaenia have also been reported after viral hepatitis. In contrast we have observed one patient who developed thrombocytosis during the disease. Rarely fatal aplastic anaemia may develop within a few weeks of hepatitis but the pathogenesis of this complication remains to be established (Levy et al., 1965). 
Fifteen of the patients described by Conrad et al. (1964) had proteinuria, ten significant haematuria and five casts in the urine (two had red cell casts). Renal biopsies were performed in twenty patients and no pathognomonic renal lesions were seen but all specimens showed abnormalities. The most common finding was a moderate to marked hyaline granular tubular change, with swelling of the tubular epithelium, diffuse or focal interstitial oedema, and the deposition of protein in Bowman's space. Large droplets, which stained positively with periodic acid-Schiff, were observed within the proximal tubular epithelium in most specimens. Mild glomerular lesions consisting of diffuse glomerular swelling, which obliterated Bowman's space, were seen in ten specimens. There were focal areas of hypercellularity, and six biopsies showed definite thickening of Bowman's space. In three there was focal thickening of the basement membrane. One year after the onset of clinical illness kidney biopsy specimens from five patients showed no histological abnormalities.

In addition an inflammatory lesion was observed in biopsy specimens of the stomach and small intestinal mucosa. These showed lymphoid infiltration of the villous stroma and lamina propria during the phase of acute illness. The infiltrates were diffuse and contained lymphocytes, histiocytes and plasma cells. Later, during convalesence, they formed discrete aggregates of various sizes separated by fibrous connective tissue. In addition mast cells were scattered throughout the villous stroma and lamina propria. Similar changes in intestinal biopsies during acute hepatitis were described by Astaldi et al. (1964). These histological changes in the small intestine must be interpreted with some reserve because of the normal infiltration of this tissue with mononuclear cells. However, the findings are suggestive of an inflammatory change in the small bowel.

Acute viral hepatitis is therefore a generalized disease with the clinical accent falling on the acute inflammatory changes in the liver.

\section{Fulminating hepatitis}

Fortunately fulminating hepatitis is a rare complication of infective hepatitis. It has a very high mortality (Katz et al., 1962 ; Sherlock, 1963 ; MacDonald \& de la Harpe, 1963). These patients may present with confusion, rapidly developing stupor and coma. Children may be acutely maniacal. In a number of patients the illness commences in the usual way, only to be followed by the development of profuse vomit- ing, deepening jaundice and a rapid reduction in liver size. This is soon followed by confusion, a flapping tremor, foetor hepaticus, stupor, coma and death. During the past 4 years we have seen thirty patients with this syndrome, and we have reported the results of the use of exchange blood transfusion in some of these desperately ill patients (Trey, Burns \& Saunders, 1966; Saunders, 1967). It is clear that some patients do respond to exchange blood transfusions, and are restored to a normal level of consciousness. However, other patients do not respond at all to repeated exchange blood transfusions, and this has also been the experience of others (Saunders, 1967). Trey et al. (1967) have described the production of hepatic coma in monkeys following on the intraportal injection of carbon tetrachloride, and have successfully reversed coma in these animals by means of exchange blood transfusions. This provides experimental support for the claim that exchange transfusion is successful in some of these patients. Morris, Grock \& Sardi (1967) have shown that the effectiveness of exchange transfusion in dogs with fulminant viral hepatitis may be due to the presence of a specific neutralizing antibody in the donor blood. Eiseman (1967) has described the perfusion of the isolated pigo liver in forty-five patients in hepatic coma, ans eight of them recovered consciousness as a resulto of this procedure. Watts et al. (1967) have also reported the successful use of isolated pig liver perfusion. Unlike exchange blood transfusion the use of the pig liver presents certain technical difficulties, but it is possible that these two methods will prove to be complementary in the treatment of these patients.

The workers from Seattle (Burnell et al., 1967) have used cross-circulation with human volunteers and have shown that hepatic coma may be reversed in this way. Of interest is the fact that none of the donors developed any evidence of encephalopathy.

All these procedures aim at allowing time for regeneration of the liver to take place, and recovery can be complete although cirrhosis develops in some patients (Saunders, 1967). It must be emphasized that during the acute phase of the illness, once the coma has been reversed, these patients are liable to other complications such as severe haemorrhage, hypoglycaemia, infection and hypoalbuminaemia.

Patients who fail to respond to exchange blood transfusion and to the perfusion of the isolated liver of the pig will ultimately be treated by transplantation of the liver, when this procedure becomes clinically feasible. 


\section{Acknowledgments}

The work in this paper was supported by the Staff Research Fund of the University of Cape Town and by the F. Mellish Memorial Fund.

\section{References}

Allen, J.G. \& Sayman, W.A. (1962) Serum hepatitis from transfusions of blood: Epidemiologic study. J. Amer. med. Ass. 180, 1079.

Astaldi, G., Grandini, U., Poggi, C. \& Stosselli, E. (1964) Intestinal biopsy in acute hepatitis. Amer. J. dig. Dis. 9, 237.

Burnell, J.M., Dawborn, J.K., Epstein, R.B., Gutman, R.A., Leinbach, G.E., Thomas, E.D. \& Volwiler, W. (1967) Acute hepatic coma treated by cross circulation or exchange transfusion. New Engl. J. Med. 276, 936.

Chung, W.K., Moon, S.K., Gershon, R.K., Price, A.M. \& Popper, H. (1964) Anicteric hepatitis in Korea. (ii) Serial histological studies. Arch. intern. Med. 113, 535.

Conrad, M.E., Schwartz, F.D. \& Young, A.A. (1964) Infectious hepatitis-a generalized disease. Amer. J. Med. 37, 789.

Cooper, W.C., Gershon, R.K., Sun, S.-H. \& Fresh, J.W. (1966) Anicteric viral hepatitis. New Engl.J. Med. 274, 585.

Cullinan, E.R., KING, R.C. \& Rivers, J.S. (1958) The prognosis of infective hepatitis. Brit. med. J. i, 1315.

De Ritis, F., Mallucci, L., Coltorti, M., Giusti, G. \& Caldera, M. (1959) Anicteric virus hepatitis in a closed environment as shown by serum transaminase activity. Bull. Wld Hlth Org. 20, 589.

DraKe, M.E. \& MiNG, C. (1954) Gammaglobulin in epidemic hepatitis. J. Amer. med. Ass. 115, 1302.

Eiseman, B. (1967) Hepatic perfusion. Proceedings of the Colston Research Society Symposium: The Liver. Blackwell Scientific Publications, Oxford.

Hampers, C.L., Prager, D. \& Senior, J.R. (1964) Post transfusion anicteric hepatitis. New Engl. J. Med. 271, 747.

Hoxworth, P.I., Haesler, W.E., JR \& SMITh, H., JR (1959) The risk of hepatitis from whole blood and stored plasma. Surg. Gynec. Obstet. 109, 38.

Katz, R., Velasco, M., Klinger, J. \& Alessandri, H. (1962) Corticosteroids in treatment of acute hepatitis in coma. Gastroenterology, 42, 258.

Klatskin, G. (1958) Subacute hepatic necrosis and post necrotic cirrhosis due to anicteric infection with hepatitis virus. Amer. J. Med. 25, 333.
Levy, R.N., Sawitsky, A., Florman, A.L. \& Rubin, E. (1965) Fatal aplastic anemia after hepatitis. New Engl. J. Med. 273, 1118.

McDonald, R. \& de la HaRpe, P.L. (1963) Hepatic coma in childhood. J. Pediat. 63, 916.

Mirick, G.S., Ward, R. \& McCollum, R.W. (1965) Modification of post transfusion hepatitis by gamma globulin. New Engl. J. Med. 273, 59.

Morris, T.Q., Grocke, D.J. \& SARDI, G.F. (1967) Exchange transfusion treatment of fulminating viral hepatitis in the dog. J. clin. Invest. 46, 1098.

Nefzger, M.D. \& Chalmers, T.C. (1963) The treatment of acute infectious hepatitis. Ten year follow up study of the effects of diet and rest. Amer. J. Med. 35, 299.

Rightsel, W.A. (1967) Isolation of viruses from patients with hepatitis. Proceedings of the Colston Research Society Symposium: The Liver. Blackwell Scientific Publications, Oxford.

SAUNDERS, S.J. (1967) The treatment of hepatic coma by exchange blood transfusion. Proceedings of the Colston Research Society Symposium: The Liver. Blackwell Scientific Publications, Oxford.

Shaefer, S.W., Schiff, L., Gall, E.A. \& Oikawa, Y. (1967) Progression of acute hepatitis to postnecrotic cirrhosis. Amer. J. Med. 42, 348.

SHERLOCK, S. (1963) Diseases of the Liver and Biliary System, 3rd edn, p. 85. Blackwell Scientific Publications, Oxford.

ShimuzU, Y. \& Kitamoto, O. (1963) The incidence of viral hepatitis after blood transfusions. Gastroenterology, 44, 740.

Stokes, J., JR (1962) The control of viral hepatitis. Amer.J. Med. 32, 729.

Trey, C., Burns, D.G. \& Saunders, S.J. (1966) Treatment of hepatic coma by exchange blood transfusion. New Engl. J. Med. 274, 473.

Trey, C., King, N.W., Garcia, F.G. \& Davidson, C.S. (1967) Reproduction of fulminant hepatic necrosis in Rhesus monkeys and the reversal of hepatic coma by exchange transfusion. J. clin. Invest. 46, 1125.

Watts, J.McK., Douglas, M.C., Dudley, H.A.F., GurR, F.W. \& OWEN, J.A. (1967) Heterologous liver perfusion in acute hepatic failure. Brit. med. J. ii, 341.

Zieve, L., Hill, E., Nesbitts, S. \& Zieve, B. (1953) The incidence of residuals of viral hepatitis. Gastroenterology, 25, 495.

\title{
A 'burnt-out' case of sarcoidosis
}

\author{
J. G. SCADDING \\ Institute of Diseases of the Chest, Brompton, London
}

SARCoIDosis has a strong tendency to spontaneous resolution, and there is good evidence that sarcoid granulomas can disappear leaving no evidence of their former presence. The granulomas may persist for several years without becoming fibrotic, apparently still capable of resolution; but if they fail to resolve, they generally undergo hyaline fibrosis. In this fibrosis, there may eventually be little or no recognizable remnant of the original epithelioid cell granuloma. Necropsy findings at this very late stage of the disease may be non-specific or inconclusive, even though correlation with the observed clinical course may leave no reasonable doubt of the diagnosis. This paper reports a case which illustrates this point. 